\title{
Editorial Comment on: DPP9 Increases Chemoresistance and is an Indicator of Poor Prognosis in Colorectal Cancer
}

\author{
Takehiko Yokobori, $\mathrm{MD}, \mathrm{PhD}^{1,2}$ \\ ${ }^{1}$ Department of General Surgical Science, Graduate School of Medicine, Gunma University, Maebashi, Japan; ${ }^{2}$ Research \\ Program for Omics-Based Medical Science, Division of Integrated Oncology Research, Gunma University Initiative for \\ Advanced Research (GIAR), Maebashi, Gunma, Japan
}

Colorectal cancer (CRC) is a common cancer worldwide. ${ }^{1}$ In a period without effective anticancer drugs, patients with advanced CRC have a poor prognosis. However, even in advanced cases, long-term survival may be achieved by using the latest established surgical techniques, radiotherapy, and systemic chemotherapies. Chemotherapy currently includes novel cytotoxic agents, targeted molecular antibodies, and evolving immune checkpoint inhibitors (ICI). ${ }^{2-7}$ In contrast, patients with significantly advanced or recurrent CRC who do not respond to available chemotherapeutic agents do not exhibit improved outcomes. Further research is required to identify new therapeutic targets to counter therapeutic resistance in patients with CRC.

The dipeptidyl peptidase (DPP) subfamily $9 \mathrm{~b}$ includes six members: DPP4, DPP9, DPP8, fibroblast activation protein alpha, DPP4-like protein 1, and DPP4-like protein 2. ${ }^{8}$ DPP4 is the best-known DPP family protein. It serves as a multifunctional protein involved in $\mathrm{T}$ cell activation and modulation of several chemokines, neuropeptides, and peptide hormones, such as neuropeptide $\mathrm{Y}$, substance $\mathrm{P}$, glucagon-like peptide 1, GIP, and glucagon. Several DPP4 inhibitors are currently used clinically as antidiabetic agents. ${ }^{9}$

(C) Society of Surgical Oncology 2020

First Received: 11 May 2020;

Published Online: 22 June 2020

T. Yokobori, MD, $\mathrm{PhD}$

e-mail: bori45@gunma-u.ac.jp
DPP9 has attracted attention as an inflammasome repressor in human autoinflammatory diseases. ${ }^{10}$ The inflammasome is associated with cancer progression, chemosensitivity, and regulation of immune cells in the tumor microenvironment. ${ }^{11-14}$

In this issue of Annals of Surgical Oncology, Saso et al. ${ }^{15}$ focused on the significance of DPP9 expression and the potential of DPP9 targeting for chemosensitizing tumors to conventional cytotoxic agents. The authors demonstrate that the DPP9 expression levels in CRC are higher than those in noncancerous tissues and that, in patients with CRC, high DPP9 expression levels are associated with poor prognosis compared with patients with low DPP9 expression levels. Moreover, DPP9 suppression by RNA interference (RNAi) and compounds such as talabostat and vildagliptin inhibits CRC cell viability, and the combination of existing cytotoxic agents with compounds that target DPP9 increases the sensitivity of CRC cells to chemotherapy. These data suggest that DPP9 levels in CRC tissues might be a useful marker for poor prognosis and that targeting DPP9 might be useful for chemosensitizing refractory CRC.

Interestingly, the authors discussed drug repositioning of talabostat and vildagliptin, the latter already approved as a drug for diabetes treatment, for DPP9 targeting in CRC with a view toward translational research. Indeed, talabostat reportedly activates the NLRP1b inflammasome via suppression of DPP8/9, thereby inducing the antitumor immune response. ${ }^{16}$ Furthermore, vildagliptin suppresses cancer growth via regulation of NK cell activity and activation of lymphocyte chemotaxis as part of antitumor immunity. ${ }^{17,18}$ Therefore, targeting the DPP family may enhance the therapeutic effect of ICI treatment. Saso et al. ${ }^{15}$ demonstrated that high DPP9 expression in CRC 
was significantly associated with poor prognosis and that targeting of DPP9 by existing compounds could sensitize CRC cell lines and primary cultured CRC cells to currently used cytotoxic agents such as CPT-11 and oxaliplatin.

In the future, evaluation of DPP9 expression in pre- and posttreatment samples from CRC, including body fluid, biopsies, or resected CRC before recurrence, may be promising as a biomarker to predict the sensitivity of several key drugs such as CPT-11 and oxaliplatin as well as 5-FU and molecular targeted drugs in CRC medical care. Additional clinical studies are needed to clarify whether therapeutic strategies in combination with conventional key anticancer drugs and already-established DPP9 inhibitors show significant efficacy in patients with refractory CRC with chemoresistant characteristics. Drug repositioning of talabostat and vildagliptin for patients with CRC may promote such clinical trials more rapidly than would occur with future development of new chemicals that target DPP9.

DISCLOSURES The author declares no conflicts of interest.

\section{REFERENCES}

1. Bray F, Ferlay J, Soerjomataram I, Siegel RL, Torre LA, Jemal A. Global cancer statistics 2018: GLOBOCAN estimates of incidence and mortality worldwide for 36 cancers in 185 countries. CA Cancer J Clin. 2018; 68(6):394-424.

2. Brown KGM, Solomon MJ. Progress and future direction in the management of advanced colorectal cancer. Br J Surg. 2018; 105(6):615-7.

3. Ali SM, Pawlik TM, Rodriguez-Bigas MA, Monson JRT, Chang GJ, Larson DW. Timing of surgical resection for curative colorectal cancer with liver metastasis. Ann Surg Oncol. 2018; 25(1):32-7.

4. Hawkins AT, Ford MM, Geiger TM, et al. Neoadjuvant radiation for clinical T4 colon cancer: a potential improvement to overall survival. Surgery. 2019; 165(2):469-75.

5. Dienstmann R, Salazar R, Tabernero J. Personalizing colon cancer adjuvant therapy: selecting optimal treatments for individual patients. J Clin Oncol. 2015; 33(16):1787-96.
6. Siddiqui AD, Piperdi B. KRAS mutation in colon cancer: a marker of resistance to EGFR-I therapy. Ann Surg Oncol. 2010; 17(4):1168-76.

7. Boland PM, Ma WW. Immunotherapy for colorectal cancer. Cancers. 2017; 9(5):50.

8. Wagner L, Klemann C, Stephan M, von Horsten S. Unravelling the immunological roles of dipeptidyl peptidase 4 (DPP4) activity and/or structure homologue (DASH) proteins. Clin Exp Immunol. 2016; 184(3):265-83.

9. Mishriky BM, Tanenberg RJ, Sewell KA, Cummings DM. Comparing SGLT-2 inhibitors to DPP-4 inhibitors as an add-on therapy to metformin in patients with type 2 diabetes: A systematic review and meta-analysis. Diabetes Metab. 2018; 44(2):112-20.

10. Zhong FL, Robinson K, Teo DET, et al. Human DPP9 represses NLRP1 inflammasome and protects against autoinflammatory diseases via both peptidase activity and FIIND domain binding. $J$ Biol Chem. 2018; 293(49):18864-78.

11. Karan D. Inflammasomes: Emerging central players in cancer immunology and immunotherapy. Front Immunol. 2018; 9:3028.

12. Kong H, Wang Y, Zeng X, Wang Z, Wang H, Xie W. Differential expression of inflammasomes in lung cancer cell lines and tissues. Tumour Biol. 2015; 36(10):7501-13.

13. Feng X, Luo Q, Zhang H, et al. The role of NLRP3 inflammasome in 5-fluorouracil resistance of oral squamous cell carcinoma. J Exp Clin Cancer Res. 2017; 36(1):81.

14. de Vasconcelos NM, Vliegen G, Goncalves A, et al. DPP8/DPP9 inhibition elicits canonical Nlrp1b inflammasome hallmarks in murine macrophages. Life Sci Alliance. 2019; 2(1):e201900313. h ttps://doi.org/10.26508/lsa.201900313.

15. Saso K, Miyoshi N, Fujino S, et al. DPP9 increases chemoresistance and is an indicator of poor prognosis in colorectal cancer. Ann Surg Oncol 2020. https://doi.org/10.1245/s10434-020-0872 9-7.

16. Okondo MC, Rao SD, Taabazuing CY, Chui AJ, Poplawski SE, Johnson DC, Bachovchin DA. Inhibition of Dpp8/9 activates the Nlrp1b inflammasome. Cell Chem Biol. 2018; 25(3):262-7.

17. Jang JH, Janker F, De Meester I, et al. The CD26/DPP4-inhibitor vildagliptin suppresses lung cancer growth via macrophage-mediated NK cell activity. Carcinogenesis. 2019; 40(2):324-34.

18. Nishina S, Yamauchi A, Kawaguchi T, et al. Dipeptidyl peptidase 4 inhibitors reduce hepatocellular carcinoma by activating lymphocyte chemotaxis in mice. Cell Mol Gastroenterol Hepatol. 2019; 7(1):115-34.

Publisher's Note Springer Nature remains neutral with regard to jurisdictional claims in published maps and institutional affiliations. 